\title{
Preliminary Studies for Fluorometric Determination of Pyridoxal and of Its 5'-Phosphate
}

\author{
Shigeru Takanashi and Zenzo Tamura ${ }^{1}$ \\ Faculty of Pharmaceutical Sciences, University \\ of Tokyo, Tokyo (Post No. 113)
}

(Received October 24, 1969)

\begin{abstract}
As fundamental studies fos fluorometric determination of pyridoxal and of pyridoxal phosphate in biological materials, hydrolysis of pyridoxal phosphate, condition of the reaction and fluorometry, and interfering substances were examined.
\end{abstract}

Bonavita (1) found that the reaction of pyridoxal (PAL) and of pyridoxal 5'-phosphate (PAL-P) with cyanide in a slightly alkaline solution produced highly fluorescent compounds and this reaction has been applied to fluorometric determination of PAL and PAL-P as "cyanohydrin method". Recently it was found that PAL and PAL-P were oxidized with oxygen by a catalytic action of cyanide to 4 pyridoxolactone (PiAL) and 4-pyridoxic acid 5 '-phosphate (PiA-P) respectively $(2,3)$.

The present studies deal with some fundamental works which were carried out in order to utilize the reaction to fluorometric determination of PAL and PAL-P in biological materials. The fluorescence intensity of the reaction product obatined from PAL was found to be much stronger than that from PAL-P and PAL could be more easily separated from interfering substances than PAL-P. For determination of PAL-P it is therfore preferable to determine it as PAL after hydrolysis. The hydrolysis of PAL-P, the reaction condition and interfering substances were studied.

\section{EXPERIMENTAL}

\section{Materials}

PAL, pyridoxine (PIN), pyridoxamine (PAM) and their 5'-phosphate were purchased from E. Merck Aktiengesellshaft. 4-Pyridoxic acid (PiA) and PiAL were synthesized from PAL according to the method of Heyl (4). NAD was the preparation of Sigma Co.

Rat liver acid phosphatase (P-ase) was obtained by the method of Goodlad et al. (5). Potato acid P-ase was prepared according to the method of Katsunuma et al. (6) with some modifications. Potatoes $(1 \mathrm{~kg})$ were homogenized in $500 \mathrm{ml}$ of $0.1 \mathrm{M}$ acetate buffer $(\mathrm{pH} 3.4)$ and filtered with gauze into a beaker. Celite $(40 \mathrm{~g})$ was added to the filtrate, mixed well and filtered. The filtrate was cooled to $0^{\circ}-4^{\circ}$ and $34 \mathrm{~g}$ of $\left(\mathrm{NH}_{4}\right)_{2} \mathrm{SO}_{4}$ per $100 \mathrm{ml}$ of the filtrate was added in portions under stirring. The mixture was allowed to stand for 1 hour at $0^{\circ}-4^{\circ}$ and centrifuged. Supernatant solution was discarded and the precipitate was dissolved in $0.05 \mathrm{M}$ Tris- $\mathrm{HCl}$ buffer $(\mathrm{pH} 7.2)$. The solution was dialyed twice against 5 liters of water for 12 hours. The dialysed solution was adjusted to $\mathrm{pH} 5$ with $0.1 \mathrm{M}$ acetate buffer $(\mathrm{pH} 3.4)$ and heated at $60^{\circ}$ for 1 minute. The solution was cooled to $0^{\circ}-{ }^{\circ} 4$ and centrifuged. Supernatant solution was diluted with $0.2 \mathrm{M}$ acetate buffer $(\mathrm{pH} 4.0)$ to obtain $0.4 \mathrm{unit} / \mathrm{ml}$ solution. The unit was defined as the amount of the enzyme which liberated $1 \mu$ mole of inorganic phosphate $(\mathrm{Pi})$ per minute from $20 \mu$ moles $\left(5 \times 10^{-3} \mathrm{M}\right)$ of $\beta$-glucerophosphate at $\mathrm{pH} 4.0$.

\section{Apparatus}

Excitation and emission spectra, and fluorescence intensity were measured in a Hitachi fluorescence spectrophotometer MPF-2.

\footnotetext{
1 高梨 茂, 田村善蔵.
} 
3. Reaction of PAL and of PAL-P with Cyanide

To $5 \mathrm{ml}$ of PAL or of PAL-P solution $\left(10^{-6}-10^{-7} \mathrm{M}\right)$ in $0.2 \mathrm{M}$ phosphate buffer $(\mathrm{pH} 7.5)$ was added $0.1 \mathrm{ml}$ of $0.1 \mathrm{M} \mathrm{KCN}$ solution. It was heated at $50^{\circ}$.

\section{Hydrolysis of PAL-P}

Acid hydrolysis - PAL-P $\left(5 \times 10^{-4} \mathrm{M}, 5 \mu\right.$ moles $)$ was heated in $2 \mathrm{~N} \mathrm{H}_{2} \mathrm{SO}_{4}$ or in $0.2 \mathrm{~N} \mathrm{H}_{2} \mathrm{SO}_{4}$ at $100^{\circ}$ respectively, and liberated $\mathrm{iP}$ was assayed by the method of Fiske-SubbaRow (7). PAL was assayed by fluorometry after the cyanide reaction.

Enzymatic hydrolysis - A mixture of $1 \mathrm{ml}$ of PAL-P $\left(10^{-6} \mathrm{M}\right), 2.5 \mathrm{ml}$ of $0.2 \mathrm{M}$ acetate buffer $(\mathrm{pH} 4.0)$ and $0.5 \mathrm{ml}$ of acid P-ase was incubated at $37^{\circ}$ for 1 hour. To the incubation mixture was added $1 \mathrm{ml}$ of $10 \%$ trichloroacetic acid (TCA) and the mixture was centrifuged. The supernatant solution was assayed for liberated iP and PAL.

\section{Results AND Discussion}

1. Fluorescence Intensities of the Reaction Product of PAL and of PAL-P with Cyanide

The reaction mixture of $10^{-7} \mathrm{M}$ PAL and $\mathrm{KCN}$ was adjusted to $\mathrm{pH} 10$ and the fluorescence intensity was measured at $356 \mathrm{~m} \mu$ of excitation and $432 \mathrm{~m} \mu$ of emission. In the case of PAL-P, $10^{-7} \mathrm{M}$ solution was treated with $\mathrm{KCN}$ and adjusted to $\mathrm{pH} 3$, and fluorescence intensity at $418 \mathrm{~m} \mu$, excited at $318 \mathrm{~m} \mu$, was measured. The fluorescence intensity of the former was about 5 times as strong as that of the latter. Therefore, it is favorable to measure PAL-P as PAL following hydrolysis in order to obtain higher sensitivity. Furthermore, the hydrolysis of PAL-P was advantageous for separation from interfering substances as described after.

\section{Hydrolysis of PAL-P}

As shown in Table 1, PAL-P failed to be hydrolysed completely either in 0.2 or in $2 \mathrm{~N}$ $\mathrm{H}_{2} \mathrm{SO}_{4}$. Furthermore, assayed values of PAL were lower than that of $\mathrm{iP}$, suggesting that PAL might be decomposed during the hydrolysis.

On the other hand, almost quantitative hydrolysis was archieved by the enzymatic hydrolysis. As shown in Table 2, the hydrolysis rates by rat liver acid $\mathrm{P}$-ase were about $90 \%$ at most and the enzyme contained PAL
TABLE 1

Acid hydrolysis of PAL-P

\begin{tabular}{|c|c|c|c|}
\hline & Time & $\underset{\text { liberated }}{\mathrm{Pi}}$ & $\begin{array}{c}\text { PAL } \\
\text { liberated }\end{array}$ \\
\hline \multirow{5}{*}{$\begin{array}{c}\text { PAL-P } 5 \mu \text { moles } \\
0.2 \mathrm{~N}_{100^{\circ}}^{\mathrm{H}_{2}}\end{array}$} & min. & umoles & umoles \\
\hline & 15 & 1.36 & 1.24 \\
\hline & 30 & 2.76 & 2.66 \\
\hline & 45 & 3.30 & 3.06 \\
\hline & 60 & 3.58 & 3.41 \\
\hline \multirow{4}{*}{$\begin{array}{c}\text { PAL-P } 5 \mu \text { moles } \\
2 \mathrm{~N}_{100^{\circ}}^{\mathrm{H}_{2} \mathrm{SO}_{4}}\end{array}$} & 15 & 1.55 & 1.42 \\
\hline & 30 & 2.74 & 2.44 \\
\hline & 45 & 3.64 & 3.25 \\
\hline & 60 & 4.32 & 3.56 \\
\hline
\end{tabular}

TABLE 2

Enzymatic hydrolysis of PAL-P

\begin{tabular}{ccc}
\hline \hline & $\begin{array}{c}\text { Amount of } \\
\text { enzyme }\end{array}$ & $\begin{array}{c}\text { Hydrolysis } \\
\text { rate }\end{array}$ \\
\hline & unit & per cent \\
PAL-P 1 m $\mu$ mole & 0.07 & 78 \\
Rat liver acid & 0.14 & 91 \\
phosphatase & 0.28 & 90 \\
$37^{\circ}, 60$ min & 0.56 & 82 \\
\hline & 0.05 & 81 \\
PAL-P 1 m $\mu$ mole & 0.10 & 95 \\
Potato acid & 0.15 & 99 \\
phosphatase & 0.20 & 98 \\
37 60 min & 0.25 & 98 \\
& 0.40 & 94 \\
\hline
\end{tabular}

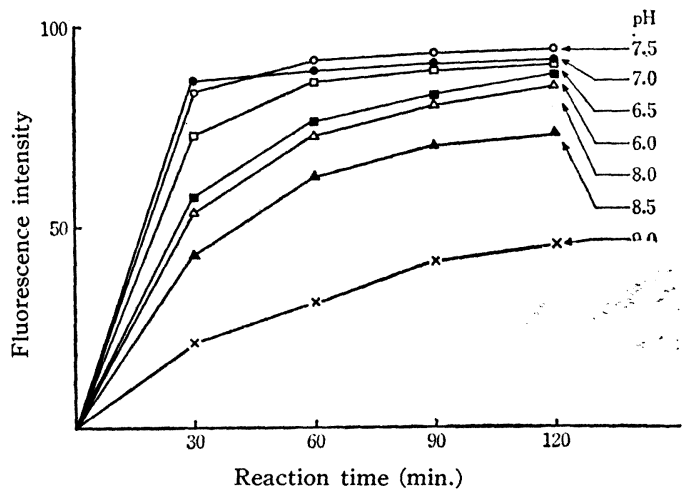

FIG. 1 Effect of $p H$ and reaction time on the reaction

or PAL-P in comparatively high concentration, while almost quantitative hydrolysis was effected by $0.15-0.2$ unit of potato acid P-ase.

3. $p H$ and Time Course of the Reaction

The reaction of $10^{-7} \mathrm{M}$ PAL with $\mathrm{KCN}$ was carried out at each $\mathrm{pH}$ level as specified in Fig. 1. An aliquot of each reaction mixture 
was taken at intervals of 30 minutes, adjusted to $\mathrm{pH} 10$ with $0.4 \mathrm{M} \mathrm{Na}_{2} \mathrm{CO}_{3}$ and fluorescence intensities were measured. The maximum intensity was obtained by the reaction at $\mathrm{pH}$ 7.5 for 1.5-2 hours (Fig. 1).

4. Effect of $p H$ on the Fluorescence Intensity

The fluorescence intensity of the reaction product of $\mathrm{PAL}$, i.e., $\mathrm{PiAL}$, reached the maximum and was stable at $\mathrm{pH}$ 9-10, decreasing markedly as the $\mathrm{pH}$ approached an acidic region. PiAL was unstable above $\mathrm{pH}$ 10. Excitation and emission maxma of PiAL at $\mathrm{pH} 10$ were 356 and $432 \mathrm{~m} \mu$ respectively.

\section{Interfering Substances}

Metallic ions, such as $\mathrm{Cu}^{2+}, \mathrm{Zn}^{2+}, \mathrm{Mg}^{2+}$ and $\mathrm{Fe}^{3+}$ in $10^{-6} \mathrm{M}$, and $10^{-4} \mathrm{M}$ EDTA showed no effect on the reaction. Glucose $\left(10^{-3} \mathrm{M}\right)$ also had little influence on the reaction. Borate inhibited the reaction markedly at the concentration of $0.1 \mathrm{M}$. Therefore, borate buffer should not be used for the reaction or pretreatment of the determination. PIN and PAM had little influence on the fluorometry even if they co-exist 10 times as much as PAL. Their fluorescence intensity was much lower than that of PiAL, and their excitation and emission maxima were 330 and $370-380$ $\mathrm{m} \mu$, respectively, at $\mathrm{pH} 10$. Since PAL itself showed only a weak fluorescence at $310 \mathrm{~m} \mu$ of excitation and $370 \mathrm{~m} \mu$ of emission at $\mathrm{pH}$ 10 , the PAL in a blank test carried out in the absence of cyanide did not interfere with the fluorometry. PiA, a metabolite of vitamin $\mathrm{B}_{6}$ group, interfered with the fluorometry because of its high fluorescence. When an equivalent amount of $\mathrm{PiA}$ co-existed with $\mathrm{PAL}$, the fluorescence intensity was increased by about $5 \%$. The reaction product of PAL$\mathrm{P}$, i.e., $\mathrm{PiA}-\mathrm{P}$, showed a fluorescence spectrum similar to that of PiA, hence PAL-P is also an interfering substance for the determination of PAL. NAD was slightly fluorescent under the reaction condition. Excitation and emission maxima of $\mathrm{KCN}$-treated $\mathrm{NAD}$ were 340 and $430 \mathrm{~m} \mu$, respectively, the values close to those of PiAL. When 100 times as much NAD as PAL co-existed, the fluorescence intensity was increased by about $15 \%$.

From these findings the preliminary separation of PAL is indespensable for the fluorometric determination of PAL and PAL-P in biological materials.

\section{Deproteinization}

Deproteinization of human sera, plasma and rat liver homogenate was examined by using TCA, perchloric acid, metaphosphoric acid and heating. As reported by Yamada et al. (8), heating at $50^{\circ}$ in the presence of TCA (final concentration, 4-5\%) gave the best result.

7. Removal of the Interfering Substances

The main interfering substances are $\mathrm{PiA}$, NAD and PAL-P for PAL determination. TCA used for the deproteinization of samples should be removed before determination. All these compounds are acidic and their removal was effected by anion exchange resins such as Amberlite IR 45 and Dowex $1 \times 8$. Detailed studies on separation of PAL shall appear in a subseqent paper. In PAL-P determination, preliminary hydrolysis makes it easier to separate from the interfering substances.

\section{REFERENCES}

1. Bonavita, V., Arch. Biochem. Biophys., 88, 366 (1960).

2. Takanashi, S., Tamura, Z., Yoshino, A., and Iidaka, Y., Chem. Pharm. Bull., 16, 758 (1968).

3. Oishi, N., and Fukui, S., Arch. Biochem. Biophys. 128, 606 (1968).

4. Heyl, D., J. Am. Chem. Soc., 70, 3434 (1948).

5. Goodlad, G. A., and Mills, G. T., Biochem. J., 66, 346 (1956).

6. Katsunuma, N., unpublished data.

7. Fiske, C. H., and SubbaRow, Y., J. Biol. Chem. 66, 375 (1925).

8. Yamada, M., and Saito A., Vitamins, 33, 361 (1966). 